\title{
Tetramethylpyrazine Protects against Hydrogen Peroxide-Provoked Endothelial Dysfunction in Isolated Rat Aortic Rings: Implications for Antioxidant Therapy of Vascular Diseases
}

\author{
Xiaojia Ni, ${ }^{1,2,3}$ Siu Ling Wong, ${ }^{3}$ Chi Ming Wong, ${ }^{3}$ Chi Wai Lau, ${ }^{3}$ Xiaogeng Shi, \\ Yefeng Cai, ${ }^{1}$ and Yu Huang ${ }^{3}$ \\ ${ }^{1}$ Guangdong Provincial Hospital of Chinese Medicine, No. 111 Dade Road, Guangzhou 510120, China \\ ${ }^{2}$ Second College of Clinical Medicine, Guangzhou University of Chinese Medicine, No. 12 Jichang Road, Guangzhou 510405, China \\ ${ }^{3}$ School of Biomedical Sciences, Chinese University of Hong Kong, Shatin, NT, Hong Kong
}

Correspondence should be addressed to Yefeng Cai; caiyefeng@126.com and Yu Huang; yu-huang@cuhk.edu.hk

Received 24 February 2014; Revised 30 July 2014; Accepted 7 August 2014; Published 2 September 2014

Academic Editor: I-Min Liu

Copyright (c) 2014 Xiaojia Ni et al. This is an open access article distributed under the Creative Commons Attribution License, which permits unrestricted use, distribution, and reproduction in any medium, provided the original work is properly cited.

\begin{abstract}
Background and Objectives. Oxidative stress can initiate endothelial dysfunction and atherosclerosis. This study evaluated whether tetramethylpyrazine (TMP), the predominant active ingredient in Rhizoma Ligustici Wallichii (chuanxiong), prevents endothelial dysfunction in a rat model of oxidative stress. Methods. Isolated rat aortic rings were pretreated with various drugs before the induction of endothelial dysfunction by hydrogen peroxide $\left(\mathrm{H}_{2} \mathrm{O}_{2}\right)$. Changes in isometric tension were then measured in acetylcholine- (ACh-) relaxed rings. Endothelial nitric oxide synthase (eNOS) expression was evaluated in the rings by Western blotting, and superoxide anion $\left(\mathrm{O}_{2}{ }^{--}\right)$content was assessed in primary rat aortic endothelial cells by dihydroethidium(DHE-) mediated fluorescence microscopy. Results. ACh-induced endothelium-dependent relaxation (EDR) was disrupted by $\mathrm{H}_{2} \mathrm{O}_{2}$ in endothelium-intact aortic rings. $\mathrm{H}_{2} \mathrm{O}_{2}$-impaired relaxation was ameliorated by acute pretreatment with low concentrations of TMP, as well as by pretreatment with catalase and the NADPH oxidase inhibitors, apocynin and diphenyleneiodonium (DPI). TMP, apocynin, and DPI also reduced $\mathrm{O}_{2}{ }^{--}$accumulation in endothelial cells, but TMP failed to alter eNOS expression in aortic rings incubated with $\mathrm{H}_{2} \mathrm{O}_{2}$. Conclusions. TMP safeguards against oxidative stress-induced endothelial dysfunction, suggesting that the agent might find therapeutic utility in the management of vascular diseases. However, TMP's role in inhibiting NADPH oxidase and its vascular-protective mechanism of action requires further investigation.
\end{abstract}

\section{Introduction}

Excessive production of reactive oxygen species (ROS) by vascular endothelial cells contributes to endothelial dysfunction [1] which then initiates atherosclerosis [2]. Atherosclerosis is a progressive process that gradually leads to artery blockage. The clinical progression of atherosclerosis culminates in a number of devastating vascular events, including myocardial infarction and stroke [3]. Accordingly, patients with an ischemic complication of atherosclerosis experience a particularly vulnerable disease phase [4]. Currently, prevention and management of cardio-cerebrovascular diseases encompass the control of risk factors, as well as antithrombotic interventions $[5,6]$. Additional efforts are directed toward interrupting ongoing oxidative processes in the vessel wall so as to prevent ROS-provoked endothelial impairment [7]. In this regard, antioxidants, which directly remove ROS threats, are emerging as one of the more promising treatments for vascular diseases in the recent years [8].

Rhizoma Ligustici Wallichii (Chinese name, chuanxiong), or lovage tuber, is commonly used in traditional Chinese medicine to promote blood circulation. Tetramethylpyrazine (TMP) is the predominant active component of Rhizoma Ligustici Wallichii [9], and the compound is noted 
for its potent vasodilating properties [10]. Like the parental herb, TMP (also called ligustrazine) is widely used to treat vascular diseases in China, with few adverse reactions in humans [11]. TMP has a long history of use, and the latest studies report its antioxidant proficiency in animal models of ischemic reperfusion [12], atherosclerosis [13], and cerebral vasospasm [14]. However, the underlying mechanism of TMP to combat detrimental ROS production and to rescue endothelial dysfunction in artery walls remains unclear.

Hydrogen peroxide $\left(\mathrm{H}_{2} \mathrm{O}_{2}\right)$ acts as a relatively benign cell signaling molecule at low concentrations [15], but exposure of blood vessels to excessive amounts of $\mathrm{H}_{2} \mathrm{O}_{2}$ results in severe endothelial impairment [16]. In addition, $\mathrm{H}_{2} \mathrm{O}_{2}$ released during the progression of atherosclerosis is likely to worsen vascular damage [17]. In light of the protective effect of TMP in clinical and animal studies, we hypothesized that the administration of this compound to $\mathrm{H}_{2} \mathrm{O}_{2}$-compromised blood vessels could prevent endothelial dysfunction. The actions of acute TMP pretreatment on endothelium-dependent relaxation (EDR) and the protein expression levels of endothelial nitric oxide synthase (eNOS) were, therefore, evaluated in isolated rat aortic rings under various experimental conditions. We also explored the preventative effect of TMP against $\mathrm{H}_{2} \mathrm{O}_{2}$-provoked generation of the superoxide anion $\left(\mathrm{O}_{2}{ }^{--}\right)$, a particularly harmful ROS, in primary cultures of endothelial cells established from the rat aorta.

\section{Materials and Methods}

2.1. Drugs and Reagents. TMP was purchased from the National Institutes for Food and Drug Control (Beijing, China). Phenylephrine (Phe), acetylcholine (ACh), apocynin, diphenyleneiodonium (DPI), vitamin E, catalase, Tiron (4,5dihydroxy-1,3-benzene-disulfonic acid), and diethyldithiocarbamic acid (DETCA) were purchased from Sigma-Aldrich (St. Louis, MO, USA). Dihydroethidium (DHE) was purchased from Molecular Probes (Eugene, OR, USA). Losartan was purchased from Cayman Chemical Co. (Ann Arbor, MI, USA). Apocynin and losartan were dissolved in dimethyl sulfoxide (DMSO), and the other compounds were dissolved in distilled water. The DMSO vehicle did not affect AChinduced aortic ring relaxation at the concentration employed in this study $(0.1 \% \mathrm{v} / \mathrm{v})$.

2.2. Blood Vessel Preparation. All animal experiments were approved by the Animal Experimentation Ethics Committee of the Chinese University of Hong Kong (Approval no. 4362/04 M). Male Sprague Dawley rats aged 6-7 months (260-280 g) were supplied by the Animal Service Center for the Chinese University of Hong Kong and euthanized by carbon dioxide inhalation. Aortas were isolated and dissected as previously described [18].

Briefly, the thoracic segment of each aorta was excised, removed of the surrounding adipose tissue, and cut into rings approximately $3 \mathrm{~mm}$ long in ice-cold oxygenated Krebs solution that consisted of $119 \mathrm{mM} \mathrm{NaCl}, 4.7 \mathrm{mM} \mathrm{KCl}, 2.5 \mathrm{mM}$ $\mathrm{CaCl}_{2}, 1 \mathrm{mM} \mathrm{MgCl}$, $25 \mathrm{mM} \mathrm{NaHCO}_{3}, 1.2 \mathrm{mM} \mathrm{KH}_{2} \mathrm{PO}_{4}$, and
$11 \mathrm{mM}$ D-glucose. The rings were then suspended between stainless stain wires in 10-mL organ baths containing Krebs solution bubbling with $95 \% \mathrm{O}_{2}$ plus $5 \% \mathrm{CO}_{2}$ at $37^{\circ} \mathrm{C}$. A basal tension of $20 \mathrm{mN}$ was applied to all rings. The rings were exposed to $0.3 \mu \mathrm{M}$ Phe to test smooth muscle contractility and then were relaxed by the addition of $3 \mu \mathrm{M}$ ACh to assess the integrity of the endothelium. In some cases, the endothelial layer was mechanically disrupted by gently rubbing the lumen against the tips of a pair of forceps. Removal of the endothelium was confirmed by the lack of relaxation in the presence of $3 \mu \mathrm{M}$ ACh. The rings were rinsed several times in prewarmed Krebs solution until baseline tension returned and then were used in isometric tension measurement experiments, as described below.

2.3. Isometric Tension Measurement. Contraction was once again induced in the aortic rings by exposure to $0.3 \mu \mathrm{M}$ Phe. A gradient of ACh $(3 \mathrm{nM}-10 \mu \mathrm{M})$ was cumulatively added to induce relaxation of the rings when the contraction response reached a plateau, so as to obtain a concentration-response curve for ACh-mediated relaxation. The rings were again rinsed in prewarmed Krebs solution until baseline tension returned, followed by pretreatment with various compounds, as described below, and exposure to $\mathrm{H}_{2} \mathrm{O}_{2}(200 \mu \mathrm{M}, 60 \mathrm{~min})$. Thereafter, a second Ach concentration-response curve was obtained to examine any changes in the EDR imposed by $\mathrm{H}_{2} \mathrm{O}_{2}$ or the drugs.

The first series of experiments was designed to investigate whether TMP pretreatment could rescue endothelial dysfunction provoked by $\mathrm{H}_{2} \mathrm{O}_{2}$. The aortic rings were incubated with various concentrations $(100 \mu \mathrm{M}, 1 \mu \mathrm{M}$, or $10 \mathrm{nM})$ of TMP for 60 min and subsequently treated with $\mathrm{H}_{2} \mathrm{O}_{2}(200$ $\mu \mathrm{M})$ for $60 \mathrm{~min}$. For comparison, the effects of losartan (1 $\mu \mathrm{M}, 30 \mathrm{~min})$, a newly identified antioxidant agent [19], and vitamin $\mathrm{E}(100 \mu \mathrm{M}, 30 \mathrm{~min})$, a classical antioxidant [20], were also tested.

The next series of experiments was designed to explore the underlying mechanism of $\mathrm{H}_{2} \mathrm{O}_{2}$-induced EDR impairment. The rings were separately pretreated for $30 \mathrm{~min}$ with catalase $(20000 \mathrm{U} / \mathrm{mL})$, an enzyme that catalyzes the decomposition of $\mathrm{H}_{2} \mathrm{O}_{2}$ to water and molecular oxygen [21], and two inhibitors of NADPH oxidase, apocynin $(10 \mu \mathrm{M})$ and DPI $(10 \mathrm{nM})[22,23]$. After catalase, apocynin, or DPI pretreatment, the rings were exposed to $\mathrm{H}_{2} \mathrm{O}_{2}(200 \mu \mathrm{M})$ for $60 \mathrm{~min}$.

2.4. Western Blotting. Western blotting analysis was performed as previously described [24]. Briefly, aortic rings were snap frozen in liquid nitrogen and homogenized in ice-cold RIPA lysis buffer. The lysates were centrifuged, and the supernatants were collected. Protein concentrations in each sample were determined by the Lowry method. Equal amounts of protein ( $50 \mu \mathrm{g}$ per sample) were resolved in $10 \%$ sodium dodecyl sulfate- (SDS-) polyacrylamide gels and then transferred to nitrocellulose immobilon-P polyvinylidenedifluoride membranes. The membranes were blocked for $1 \mathrm{~h}$ at room temperature with $1 \%$ bovine serum albumin and incubated overnight at $4^{\circ} \mathrm{C}$ with a primary 
antibody against eNOS (1:3000) (BD Transduction Laboratories, Lexington, KY, USA) and a primary antibody against the loading control, glyceraldehyde 3-phosphate dehydrogenase (GAPDH, 1:3000) (Ambion, Austin, TX, USA). The membranes were then incubated with the corresponding horseradish peroxidase-conjugated secondary antibody (DakoCytomation, Carpinteria, CA, USA) for $1 \mathrm{~h}$ at room temperature. Immunoreactive polypeptide bands were visualized by using an enhanced chemiluminescence detection system, followed by exposure to X-ray film. Densitometry was performed by using a FluorChem documentation program (Alpha Innotech Corp., San Leandro, CA, USA) to measure the eNOS and GAPDH integrated density values (IDVs) of the aortic rings for each experimental condition.

2.5. Rat Aortic Endothelial Cell Culture. Primary rat aortic endothelial cells were cultured as previously described [25]. Briefly, aortas were isolated, cut open longitudinally, and digested with $0.2 \%$ collagenase directed against type $1 \mathrm{~A}$ collagen (Sigma-Aldrich) for $15 \mathrm{~min}$ in a $37^{\circ} \mathrm{C}$ shaking water bath. RPMI medium supplemented with $10 \%$ fetal bovine serum and $1 \%$ penicillin/streptomycin was added to the cell suspension, and the cell suspension was then centrifuged at $1500 \times \mathrm{g}$ for $10 \mathrm{~min}$. The cell pellet was resuspended in the supplemented RPMI medium, and the cells were plated into culture flask $\left(25 \mathrm{~cm}^{2}\right)$ and allowed to settle for $1 \mathrm{~h}$. At this time, the medium was changed to remove nonadherent cells. After the adherent cells reached $80 \%$ confluence, they were seeded onto coverslips in 6-well trays, pretreated with various drugs as described below, exposed to $\mathrm{H}_{2} \mathrm{O}_{2}(200 \mu \mathrm{M}$, $60 \mathrm{~min})$, and subjected to DHE-mediated fluorescence microscopy for the detection of $\mathrm{H}_{2} \mathrm{O}_{2}$-generated intracellular $\mathrm{ROS} / \mathrm{O}_{2}{ }^{\cdot-}$.

\section{6. $\mathrm{ROS} / \mathrm{O}_{2}{ }^{--}$Detection via DHE-Mediated Fluorescence} Microscopy. Intracellular $\mathrm{ROS} / \mathrm{O}_{2}{ }^{--}$levels were examined in the primary rat aortic endothelial cells by using DHEmediated fluorescence microscopy. The oxidation of DHE by intracellular ROS releases ethidium, which binds to DNA to emit fluorescence. The cells were pretreated at $37^{\circ} \mathrm{C}$ with TMP (10 $\left.\mathrm{nM}, 60 \mathrm{~min}\right)$, apocynin $(10 \mu \mathrm{M}, 30 \mathrm{~min})$, DPI (10 nM, $30 \mathrm{~min})$, Tiron $(100 \mu \mathrm{M})$ plus DETCA $(1 \mathrm{mM})$ (30 min), or untreated control $(60 \mathrm{~min})$; exposed to $\mathrm{H}_{2} \mathrm{O}_{2}$ $(200 \mu \mathrm{M}, 60 \mathrm{~min})$; and then incubated with DHE $(5 \mu \mathrm{M}$, $20 \mathrm{~min})$. Tiron, an $\mathrm{O}_{2}{ }^{--}$scavenger, and DETCA, an $\mathrm{O}_{2}{ }^{--}$ generator, were utilized to confirm the production of $\mathrm{O}_{2}{ }^{--}$in the endothelial cells following exposure to $\mathrm{H}_{2} \mathrm{O}_{2}$.

After incubation with DHE, the cells were rinsed with phosphate buffered saline, and the fluorescence of DNAbound ethidium was measured under a FluoView Confocal Microscope (Olympus, Center Valley, PA, USA). The microscope was equipped with a 585-nm long pass filter and operated at an excitation wavelength of $515 \mathrm{~nm}$. The fluorescence intensity of each sample was analyzed by using FluoView FV10-ASW software, version 1.5 (Olympus). The summarized data represent fold-changes in fluorescence intensity relative to that of the control, which was set to a value of $100 \%$.
TABLE 1: Effects of TMP, losartan, and vitamin $\mathrm{E}$ on $\mathrm{H}_{2} \mathrm{O}_{2}$-provoked endothelial dysfunction in isolated rat aortic rings.

\begin{tabular}{lccc}
\hline Treatment & $\mathrm{pD}_{2}$ & $E_{\max }(\%)$ & $N$ \\
\hline Control & $7.20 \pm 0.12$ & $6.97 \pm 3.32$ & 4 \\
$\mathrm{H}_{2} \mathrm{O}_{2}(200 \mu \mathrm{M})$ & $6.40 \pm 0.23^{*}$ & $57.86 \pm 8.24^{*}$ & 6 \\
TMP $(100 \mu \mathrm{M})+\mathrm{H}_{2} \mathrm{O}_{2}$ & $7.05 \pm 0.22^{\#}$ & $16.59 \pm 9.15^{\#}$ & 5 \\
TMP $(1 \mu \mathrm{M})+\mathrm{H}_{2} \mathrm{O}_{2}$ & $7.29 \pm 0.17^{\#}$ & $23.31 \pm 9.69^{\#}$ & 5 \\
TMP $(10 \mathrm{nM})+\mathrm{H}_{2} \mathrm{O}_{2}$ & $7.07 \pm 0.15^{\#}$ & $30.38 \pm 11.25$ & 5 \\
Losartan $(1 \mu \mathrm{M})+\mathrm{H}_{2} \mathrm{O}_{2}$ & $7.02 \pm 0.17^{\#}$ & $28.36 \pm 8.15^{\#}$ & 5 \\
Vitamin $\mathrm{E}(100 \mu \mathrm{M})+\mathrm{H}_{2} \mathrm{O}_{2}$ & $6.94 \pm 0.37$ & $57.23 \pm 11.97$ & 5 \\
\hline
\end{tabular}

Data represent the mean \pm the SEM of 4-6 independent experiments $\left({ }^{*} \mathrm{P}<\right.$ 0.05 versus control; ${ }^{\#} P<0.05$ versus $\mathrm{H}_{2} \mathrm{O}_{2}$ ).

$E_{\max }$ : maximal response; $\mathrm{H}_{2} \mathrm{O}_{2}$ : hydrogen peroxide; $\mathrm{pD}_{2}$ : negative logarithm of the $\mathrm{EC}_{50}$; SEM: standard error of the mean; TMP: tetramethylpyrazine.

2.7. Statistical Analysis. All quantifiable data are expressed as the mean \pm the standard error of the mean (SEM). GraphPad Prism software, version 6.0 (GraphPad Software, Inc., La Jolla, CA, USA), was used for data analysis. The vasorelaxing effect of TMP and other drugs was expressed as the percentage reduction of the Phe-evoked contraction. Nonlinear regression curve fitting was performed on individual cumulative Ach concentration-response curves to estimate the $E_{\max }$ (maximal response) and the $\mathrm{pD}_{2}$ (negative logarithm of the $\mathrm{EC}_{50}$, where the $\mathrm{EC}_{50}$ represents the drug concentration that induces $50 \%$ of $\left.E_{\max }\right)$ for each experimental agent $\left(\mathrm{H}_{2} \mathrm{O}_{2}\right.$ or drug) or combination of agents. Thus, $E_{\max }$ is a measure of effectiveness and $\mathrm{pD}_{2}$ is a measure of potency.

The concentration-response curves were analyzed by two-way analysis of variance (ANOVA) followed by the Bonferroni post hoc test. The statistical significance of the Western blotting data and the DHE-mediated fluorescence microscopy data was determined by one-way ANOVA followed by the Bonferroni post hoc test. In each case, a $P$ value of less than 0.05 was considered significant.

\section{Results}

3.1. TMP Protects against $\mathrm{H}_{2} \mathrm{O}_{2}$-Provoked Endothelial Dysfunction. Phe $(0.3 \mu \mathrm{M})$ was utilized to provoke contraction in aortic rings isolated from adult Sprague Dawley rats, while ACh was employed to induce EDR in the Phe-contracted rings. ACh-induced EDR was markedly impaired in the rat aortic rings after $60 \mathrm{~min}$ exposure to $\mathrm{H}_{2} \mathrm{O}_{2}(200 \mu \mathrm{M})$ (Table 1, Figure 1). However, TMP pretreatment for $60 \mathrm{~min}$ at concentrations of $10 \mathrm{nM}, 1 \mu \mathrm{M}$, and $100 \mu \mathrm{M}$ significantly reversed the endothelial impairment provoked by $\mathrm{H}_{2} \mathrm{O}_{2}$. TMP and losartan, the newly identified antioxidants, showed similar effects at $1 \mu \mathrm{M}$ (Table 1 ), while pretreatment with $100 \mu \mathrm{M}$ vitamin $\mathrm{E}$, a classical antioxidant, did not greatly reverse the endothelial damage (Table 1, Figure 1).

\section{2. $\mathrm{H}_{2} \mathrm{O}_{2}$-Provoked Endothelial Dysfunction Is Reversed by} Catalase and NADPH Oxidase Inhibitors. Catalase is a $\mathrm{H}_{2} \mathrm{O}_{2}$ scavenger that reduces $\mathrm{H}_{2} \mathrm{O}_{2}$ levels by converting the superoxide anions into water and molecular oxygen. Catalase $(20000 \mathrm{U} / \mathrm{mL}, 30 \mathrm{~min})$ pretreatment of rat aortic 
TABLE 2: Effects of catalase, apocynin, and DPI on $\mathrm{H}_{2} \mathrm{O}_{2}$-provoked endothelial dysfunction in isolated rat aortic rings.

\begin{tabular}{lccc}
\hline Treatment & $\mathrm{pD}_{2}$ & $E_{\max }(\%)$ & $N$ \\
\hline Control & $7.22 \pm 0.07$ & $5.32 \pm 2.93$ & 4 \\
$\mathrm{H}_{2} \mathrm{O}_{2}(200 \mu \mathrm{M})$ & $4.63 \pm 0.25^{*}$ & $59.88 \pm 6.44^{*}$ & 6 \\
Catalase $(20000 \mathrm{U} / \mathrm{mL})+\mathrm{H}_{2} \mathrm{O}_{2}$ & $6.10 \pm 0.07^{\#}$ & $26.11 \pm 6.34^{\#}$ & 4 \\
Apocynin $(10 \mu \mathrm{M})+\mathrm{H}_{2} \mathrm{O}_{2}$ & $6.51 \pm 0.13^{\#}$ & $27.31 \pm 10.51^{\#}$ & 4 \\
DPI $(10 \mathrm{nM})+\mathrm{H}_{2} \mathrm{O}_{2}$ & $6.33 \pm 0.09^{\#}$ & $16.88 \pm 8.82^{\#}$ & 4 \\
\hline
\end{tabular}

Data represent the mean \pm the SEM of 4-6 independent experiments $\left({ }^{*} P<\right.$ 0.05 versus control; ${ }^{\#} P<0.05$ versus $\mathrm{H}_{2} \mathrm{O}_{2}$ ).

DPI: diphenyleneiodonium; $E_{\max }$ : maximal response; $\mathrm{H}_{2} \mathrm{O}_{2}$ : hydrogen peroxide; $\mathrm{pD}_{2}$ : negative logarithm of the $\mathrm{EC}_{50}$; $\mathrm{SEM}$ : standard error of the mean.

TABLE 3: eNOSIDV/GAPDH IDV ratios in isolated rat aortic rings.

\begin{tabular}{lcc}
\hline Treatment & Ratio & $N$ \\
\hline Phe $(0.3 \mu \mathrm{M})$ & $1.10 \pm 0.08$ & 5 \\
Phe $+\mathrm{ACh}(10 \mu \mathrm{M})$ & $1.24 \pm 0.04$ & 8 \\
$\mathrm{H}_{2} \mathrm{O}_{2}(200 \mu \mathrm{M})$ & $1.13 \pm 0.03$ & 8 \\
$\mathrm{TMP}(10 \mathrm{nM})+\mathrm{H}_{2} \mathrm{O}_{2}$ & $1.01 \pm 0.03$ & 6 \\
Losartan $(1 \mu \mathrm{M})+\mathrm{H}_{2} \mathrm{O}_{2}$ & $1.13 \pm 0.05$ & 6 \\
Endothelium removal & $0.32 \pm 0.04$ & 6 \\
\hline
\end{tabular}

Data represent the mean \pm the SEM of 5-8 independent experiments. ACh: acetylcholine; eNOS: endothelial nitric oxide synthase; GADPH: glyceraldehyde 3-phosphate dehydrogenase; $\mathrm{H}_{2} \mathrm{O}_{2}$ : hydrogen peroxide; IDV: integrated density value; Phe: phenylephrine; TMP: tetramethylpyrazine.

rings significantly prevented the $\mathrm{H}_{2} \mathrm{O}_{2}$-mediated disruption of ACh-induced EDR, albeit only partially (Table 2, Figure 2), suggesting that $\mathrm{H}_{2} \mathrm{O}_{2}$ exerts both direct and indirect effects to induce endothelial dysfunction. In support of this hypothesis, separate pretreatment of the rings with the NADPH oxidase inhibitors, apocynin $(10 \mu \mathrm{M}, 30 \mathrm{~min})$ and DPI (10 nM, $30 \mathrm{~min})$, also significantly blocked the induction of vascular dysfunction by $\mathrm{H}_{2} \mathrm{O}_{2}$ (Table 2, Figure 2).

3.3. TMP Does Not Rescue EDR by Altering eNOS Expression. Nitric oxide acts as a vasodilator and is produced through the actions of eNOS in the endothelium. Therefore, we reasoned that agents with the capacity to influence the EDR in rat aortic rings might have an effect on eNOS expression. However, none of the experimental conditions employed (Phe; Phe plus ACh; $\mathrm{H}_{2} \mathrm{O}_{2}(200 \mu \mathrm{M}, 60 \mathrm{~min})$; TMP (10 nM, $60 \mathrm{~min})$ plus $\mathrm{H}_{2} \mathrm{O}_{2}$; or losartan $(1 \mu \mathrm{M}, 30 \mathrm{~min})$ plus $\mathrm{H}_{2} \mathrm{O}_{2}$ ) had any effect on eNOS expression in aortic rings with an intact endothelium, as assessed on Western blots (Figure 3 ) and by comparing the eNOS IDV/GAPDH IDV ratio for each experimental condition (Table 3, Figure 3). On the other hand, the endothelium-denuded group with no drug treatment showed significantly decreased eNOS expression relative to any group with an intact endothelium (Table 3, Figure 3).

3.4. TMP, NADPH Oxidase Inhibitors, and the ROS Scavenger, Tiron, Prevented the Production of $\mathrm{O}_{2}{ }^{--}$in $\mathrm{H}_{2} \mathrm{O}_{2}-$ Exposed Rat Aortic Endothelial Cells. Finally, we evaluated
TABLE 4: DHE-mediated fluorescence microscopy assay in primary rat aortic endothelial cells.

\begin{tabular}{lcc}
\hline Treatment & $\begin{array}{c}\text { Fluorescence intensity } \\
\text { (\% of control) }\end{array}$ & $N$ \\
\hline Control & $100 \pm 0$ & 7 \\
$\mathrm{H}_{2} \mathrm{O}_{2}(200 \mu \mathrm{M})$ & $158 \pm 1.16^{*}$ & 9 \\
$\mathrm{TMP}(10 \mathrm{nM})+\mathrm{H}_{2} \mathrm{O}_{2}$ & $86 \pm 2.10^{\#}$ & 5 \\
Apocynin $(10 \mu \mathrm{M})+\mathrm{H}_{2} \mathrm{O}_{2}$ & $88.30 \pm 2.25^{\#}$ & 4 \\
DPI $(10 \mathrm{nM})+\mathrm{H}_{2} \mathrm{O}_{2}$ & $87.28 \pm 5.40^{\#}$ & 3 \\
Tiron $(100 \mu \mathrm{M})+$ DETCA $(1 \mathrm{mM})$ & $67.95 \pm 2.81^{\#}$ & 4 \\
$+\mathrm{H}_{2} \mathrm{O}_{2}$ & \\
\hline
\end{tabular}

Data represent the means \pm the SEM of 3-9 independent experiments $\left({ }^{*} \mathrm{P}<\right.$ 0.05 versus control; ${ }^{\#} P<0.05$ versus $\mathrm{H}_{2} \mathrm{O}_{2}$ ).

DHE: dihydroethidium; DETCA: diethyldithiocarbamic acid; DPI: diphenyleneiodonium; $\mathrm{H}_{2} \mathrm{O}_{2}$ : hydrogen peroxide; SEM: standard error of the mean; TMP: tetramethylpyrazine.

the ROS $/ \mathrm{O}_{2}{ }^{--}$content in primary cultures of $\mathrm{H}_{2} \mathrm{O}_{2}$-exposed rat aortic endothelial cells with and without drug pretreatment, because $\mathrm{O}_{2}{ }^{-{ }^{-}}$is a highly damaging species linked to substantial cytotoxicity in vascular endothelial cells. $\mathrm{H}_{2} \mathrm{O}_{2}$ ( $200 \mu \mathrm{M}, 60 \mathrm{~min}$ ) triggered substantial ROS generation compared with the control group, as determined by a significant increase in fluorescence intensity attributable to ethidiumbound DNA. However, the fluorescence intensity was significantly blocked by pretreatment with TMP $(10 \mathrm{nM}, 60 \mathrm{~min})$, apocynin $(10 \mu \mathrm{M}, 30 \mathrm{~min}), \mathrm{DPI}(10 \mathrm{nM}, 30 \mathrm{~min})$, or Tiron (an ROS scavenger) (100 $\mu \mathrm{M}, 30 \mathrm{~min}$ ) plus DETCA (a superoxide dismutase inhibitor that increases intracellular $\mathrm{O}_{2}{ }^{-1}$ content) (1 mM, $30 \mathrm{~min}$ ) (Table 4, Figure 4).

\section{Discussion}

Vascular events (death from all vascular causes, nonfatal stroke, or nonfatal myocardial infarction) are complex occurrences caused by multiple factors, and ROS-induced endothelial injury is suggested to be the common denominator in most vascular conditions [26]. Consequently, antioxidant therapy, which directly targets the common mediator of vascular disorders, shows great promise for the prevention and management of cardio-cerebrovascular diseases.

The current study explored the capacity of acute pretreatment with TMP, an antioxidant constituent of Rhizoma Ligustici Wallichii, to overturn the $\mathrm{H}_{2} \mathrm{O}_{2}$-mediated impairment of ACh-induced relaxation in the rat aorta. We found that the exposure of rat aortic rings to TMP prior to $\mathrm{H}_{2} \mathrm{O}_{2}$ treatment did indeed thwart the actions of $\mathrm{H}_{2} \mathrm{O}_{2}$ to promote endothelial dysfunction (Table 1, Figure 1). TMP was effective at surprisingly low doses (i.e., nM levels), yet vitamin E, a classical antioxidant, did not provide the same protective benefits at a considerably higher concentration $(100 \mu \mathrm{M})$ (Table 1, Figure 1). This may be due to the use of high concentration of $\mathrm{H}_{2} \mathrm{O}_{2}(200 \mu \mathrm{M})$ to induce impaired EDR and the potent antioxidant effect of TMP. The protective effect of TMP by reduction of oxidative stress in the present study is consistent with other studies working in different systems [12, 13, 27-29]. 

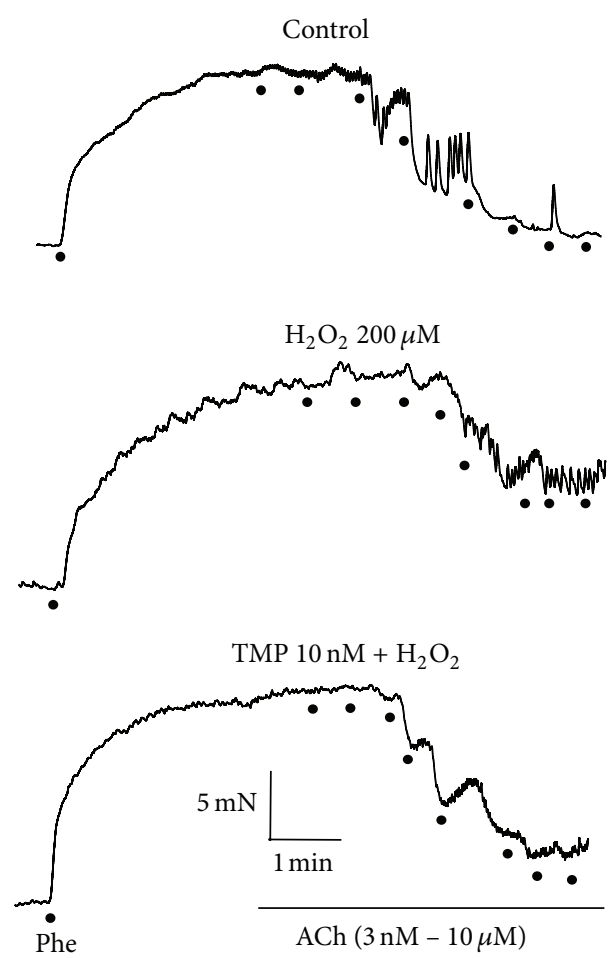

(a)

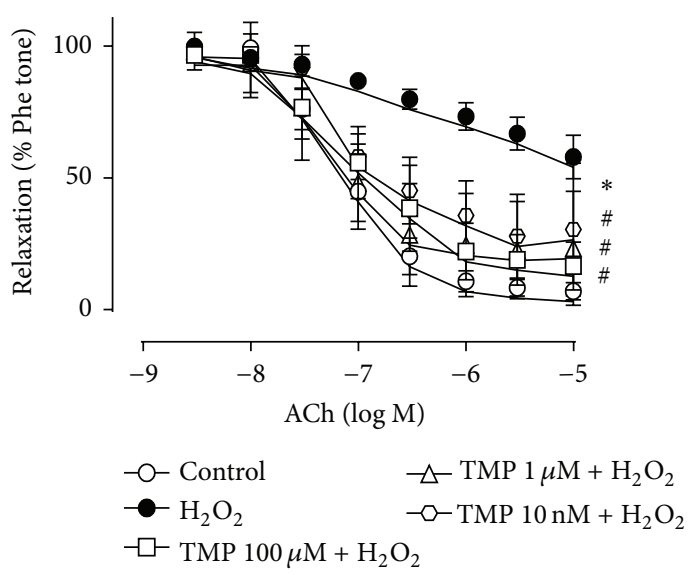

(b)

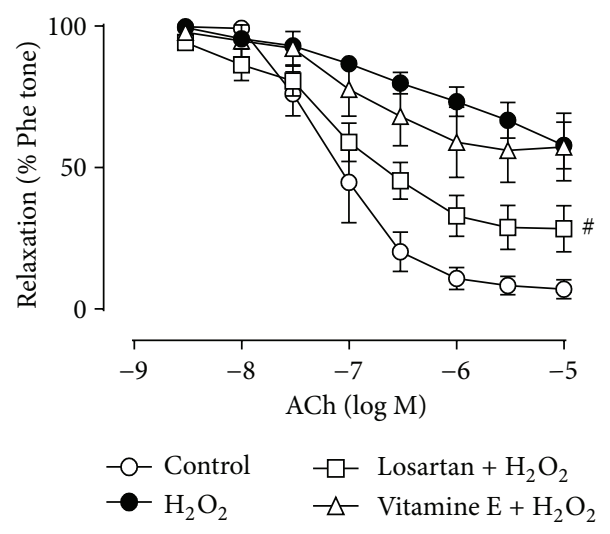

(c)

Figure 1: Tetramethylpyrazine (TMP) protects against hydrogen peroxide- $\left(\mathrm{H}_{2} \mathrm{O}_{2}-\right)$ induced endothelial dysfunction. Phenylephrine (Phe, $0.3 \mu \mathrm{M})$ was utilized to provoke contraction in isolated rat aortic rings, and acetylcholine ( $\mathrm{ACh}, 3 \mathrm{nM}-10 \mu \mathrm{M})$ was utilized to induce EDR in the Phe-contracted rings. (a) Representative traces of ACh-induced EDR in $\mathrm{H}_{2} \mathrm{O}_{2}(200 \mu \mathrm{M})$-exposed rings, with and without TMP (10 nM) pretreatment, and control rings. (b), (c) Effects of various drug treatments on $\mathrm{H}_{2} \mathrm{O}_{2}$-provoked disruption of ACh-induced EDR. The graphs share the same data for the control and $\mathrm{H}_{2} \mathrm{O}_{2}$-treated groups. Data represent the mean \pm the standard error of the mean (SEM) of 4-6 independent experiments $\left({ }^{*} P<0.05\right.$ versus control; ${ }^{\#} P<0.05$ versus $\left.\mathrm{H}_{2} \mathrm{O}_{2}\right)$.

$\mathrm{H}_{2} \mathrm{O}_{2}$ is a relatively stable ROS with dual functions in the vasculature, depending on its effective concentration. For example, low levels of $\mathrm{H}_{2} \mathrm{O}_{2}$ maintain the physiology of vascular endothelial cells [30], and $\mathrm{H}_{2} \mathrm{O}_{2}$ seldom exerts vascular damage in the absence of unpaired electrons [31]. Therefore, drugs which are capable of stimulating superoxide dismutase to transform $\mathrm{O}_{2}{ }^{-{ }^{-}}$into oxygen and $\mathrm{H}_{2} \mathrm{O}_{2}$ are regarded as protective agents [32]. However, increasing evidence demonstrates that substantial exposure to $\mathrm{H}_{2} \mathrm{O}_{2}$ at high concentrations (i.e., $>100 \mu \mathrm{M}$ ) contributes to vascular injury and associated inflammatory responses, vascular endothelial cell cytotoxicity and apoptosis, and even vascular events [33]. The present study therefore exposed the isolated rat aortic rings to high levels of $\mathrm{H}_{2} \mathrm{O}_{2}(200 \mu \mathrm{M})$ for $60 \mathrm{~min}$, with the goal of establishing an in vitro model of oxidative stressinduced endothelial dysfunction. Given that ACh-induced relaxation is endothelium-dependent and reflects normal endothelium functionality [34], $\mathrm{H}_{2} \mathrm{O}_{2}$-induced disruption of 


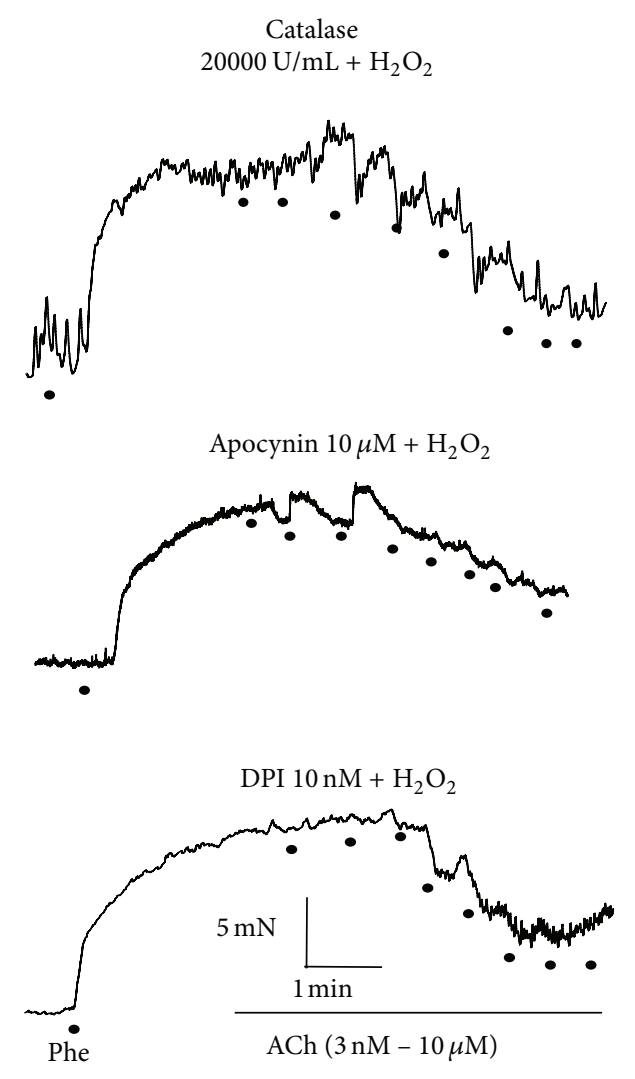

(a)

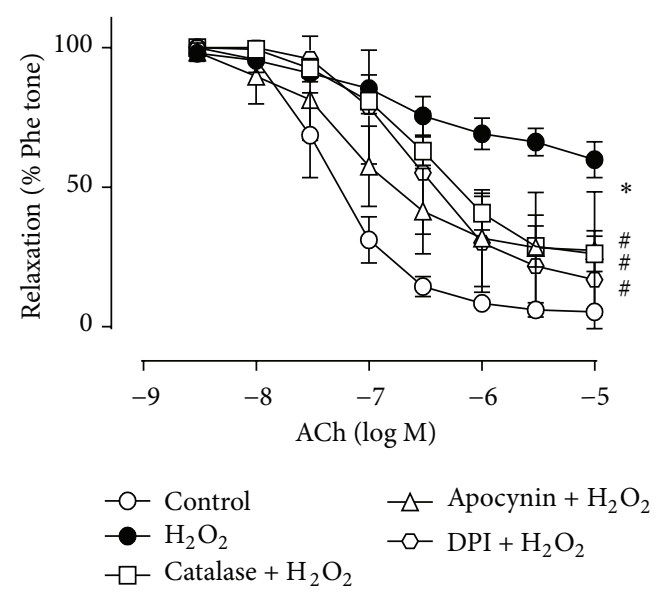

(b)

FIgURE 2: Hydrogen peroxide $\left(\mathrm{H}_{2} \mathrm{O}_{2}\right)$-induced endothelial dysfunction is reversed by catalase and NADPH oxidase inhibitors. (a) Representative traces of acetylcholine- (ACh-) induced endothelium-dependent relaxation (EDR) in $\mathrm{H}_{2} \mathrm{O}_{2}-(200 \mu \mathrm{M})$ treated rings with catalase $(20000 \mathrm{U} / \mathrm{mL})$, apocynin $(10 \mu \mathrm{M})$, or diphenyleneiodonium (DPI, $10 \mathrm{nM}$ ) pretreatment. (b) Effects of catalase, apocynin, and DPI on $\mathrm{H}_{2} \mathrm{O}_{2}$-provoked disruption of ACh-induced EDR. Data represent the mean \pm the standard error of the mean (SEM) of 4-6 independent experiments $\left({ }^{*} \mathrm{P}<0.05\right.$ versus control; ${ }^{\#} \mathrm{P}<0.05$ versus $\mathrm{H}_{2} \mathrm{O}_{2}$ ).

ACh-stimulated EDR mimics the pathophysiology of ROStriggered vascular diseases.

Interestingly, TMP or losartan pretreatment of $\mathrm{H}_{2} \mathrm{O}_{2}$ exposed aortic rings did not rescue EDR by altering eNOS expression (Table 3, Figure 3), although $\mathrm{H}_{2} \mathrm{O}_{2}$ reportedly affects endothelial function by modulating Enos content in the rabbit aorta [35]. In particular, low levels of the ROS exert vasorelaxing effects via eNOS upregulation of nitric oxide [35], suggesting that high concentrations of $\mathrm{H}_{2} \mathrm{O}_{2}$, such as that used herein, might impair EDR by downregulating eNOS content. Nonetheless, this was not the case (Table 3, Figure 3). The protective effect of TMP to $\mathrm{H}_{2} \mathrm{O}_{2}$-induced endothelial dysfunction in the present study may be due to the reported TMP-mediated activation of eNOS activity through PI3K/Akt and phosphorylation of eNOS at Ser1177 for increased generation of NO in myocardial ischaemia reperfusion [12]. At the same time, TMP can alleviate oxidative stress by increased total antioxidant activity and SOD1 activity [13]. Furthermore, catalase, a strong $\mathrm{H}_{2} \mathrm{O}_{2}$ scavenger [21], only partially reversed the impairment of EDR by $\mathrm{H}_{2} \mathrm{O}_{2}$ (Table 2, Figure 2). Hence,
$\mathrm{H}_{2} \mathrm{O}_{2}$ may indirectly as well as directly harm the vascular endothelium.

An earlier investigation indicated that $\mathrm{H}_{2} \mathrm{O}_{2}$ can activate $\mathrm{NADPH}$ oxidase to produce $\mathrm{O}_{2}{ }^{--}$in vitro [36]. We therefore pretreated rat aortic rings with two different NADPH inhibitors, apocynin and DPI, prior to $\mathrm{H}_{2} \mathrm{O}_{2}$ exposure and found that the drugs significantly safeguarded the aortas from ROS insult, and rescued EDR (Table 2, Figure 2). We also conducted DHE-mediated fluorescence measurements in cultured primary rat aortic endothelial cells to investigate the impact of $\mathrm{H}_{2} \mathrm{O}_{2}$ and various drugs on intracellular $\mathrm{O}_{2}{ }^{--}$ content. As a result, $\mathrm{H}_{2} \mathrm{O}_{2}$ enhanced $\mathrm{O}_{2}{ }^{--}$levels, while pretreatment with TMP, apocynin, DPI, or Tiron plus DETCA prevented this action (Table 4, Figure 4). This exciting finding implies that $\mathrm{O}_{2}{ }^{--}$is produced in response to exposure of the vascular endothelium to oxidative stress, which is potentially mediated via the stimulation of NADPH oxidase. On the other hand, it is still possible that $\mathrm{H}_{2} \mathrm{O}_{2}$ exposure to rat aortic rings may increase ROS generation from mitochondria due to increased oxidative stress. TMP could improve the impaired EDR by reduction of mitochondrial ROS production [27]. 

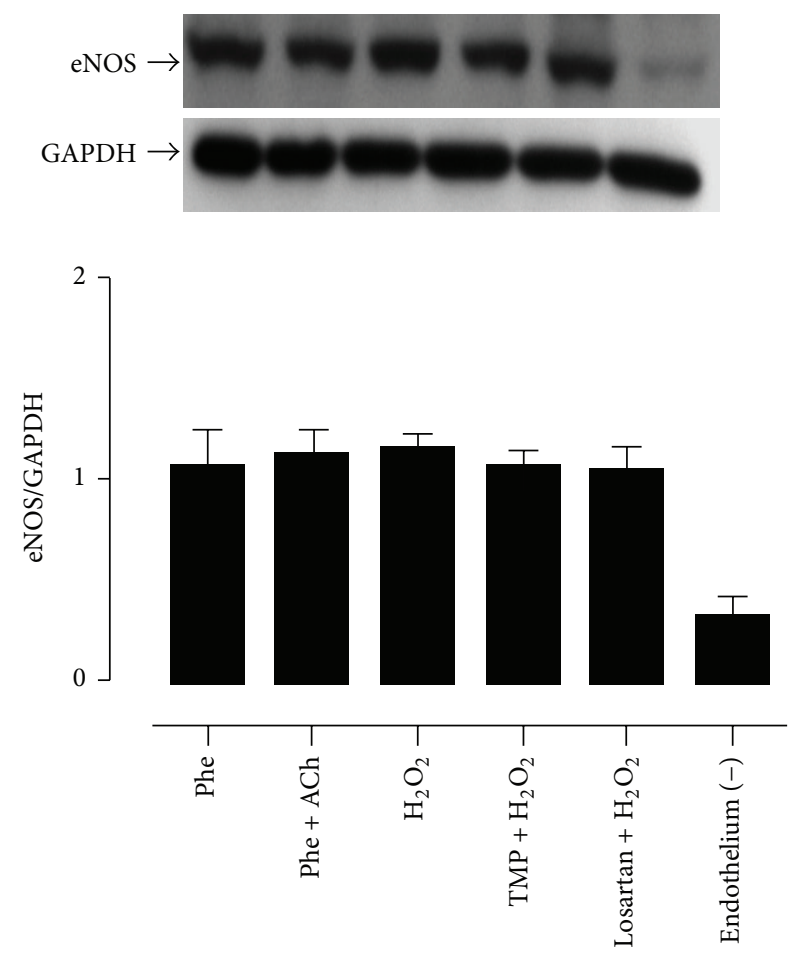

FIgURE 3: Tetramethylpyrazine (TMP) does not rescue endothelium-dependent relaxation (EDR) through actions on endothelial nitric oxide synthase (eNOS) expression. Rat aortic rings were subjected to various experimental conditions (phenylephrine (Phe); Phe plus acetylcholine (ACh); hydrogen peroxide $\left(\mathrm{H}_{2} \mathrm{O}_{2}, 200 \mu \mathrm{M}\right)$; TMP $(10 \mathrm{nM})$ plus $\mathrm{H}_{2} \mathrm{O}_{2}$; losartan $(1 \mu \mathrm{M})$ plus $\mathrm{H}_{2} \mathrm{O}_{2}$; or removal of the endothelium). The bar graph shows the ratio of the eNOS integrated density value (IDV) to the glyceraldehyde 3-phosphate dehydrogenase (GAPDH) IDV for each experimental condition. Data represent the mean \pm the standard error of the mean (SEM) of 5-8 independent experiments.

We cannot exclude this possible mechanism although its contributory role may not be significant. At the same time, it has been shown that the antioxidant effect of TMP likely is due to its ability of the mitochondrial biogenesis [28].

The possibility that TMP averts $\mathrm{H}_{2} \mathrm{O}_{2}$-provoked endothelial dysfunction by inhibiting NADPH oxidase is supported by our findings that its actions were similar to those of apocynin and DPI in both isolated aortic rings (compare Table 1 with Figure 1 and Table 2 with Figure 2) and primary aortic endothelial cells (Table 4, Figure 4). NADPH oxidase is a key generator of ROS in blood vessel walls during the progression of vascular disease [37]. An unequivocal demonstration of the TMP-mediated suppression of NADPH oxidase expression/activity under pathological conditions, with a concomitant reduction in the overproduction of $\mathrm{O}_{2}{ }^{-{ }^{-}}$and other ROS, would undeniably strengthen our proposal that TMP might serve as a new antioxidant agent for the management of vascular diseases. However, this hypothesis requires further investigation, especially in regard with determining the NADPH oxidase and $\mathrm{O}_{2}{ }^{--}$levels in rat aortic rings postTMP treatment.

Other possible alternative mechanisms may be offered by TMP to protect endothelial dysfunction. The protective effect of TMP may be due to its action to induce antiinflammatory effect in endothelium. TMP has been shown to reverse the decrease of NO production induced by TNF$\alpha$ and inhibit the downregulated expression of intracellular adhesion molecular-1 and heat shock protein 60 mediated by TNF- $\alpha$, suggesting that TMP may protect endothelium through inhibition of immunological reactions [29]. In addition, TMP treatment has been shown to prevent the increment of both inducible NO synthase and TNF- $\alpha$ expression [38], improving survival of rodent model of endotoxic shock induced by lipopolysaccharide [39]. TMP has also been demonstrated to protect streptozotocin-induced diabetic rats by downregulated expression of vascular endothelial growth factor [40].

\section{Conclusions}

In conclusion, the present study showed that TMP prevented oxidative stress-induced endothelial dysfunction in isolated rat aortic rings without affecting eNOS expression. In addition, TMP reduced $\mathrm{O}_{2}{ }^{--}$accumulation in $\mathrm{H}_{2} \mathrm{O}_{2}$-exposed primary rat aortic endothelial cells. The NADPH oxidase inhibitors, apocynin and DPI, displayed the same actions as TMP in both in vitro models. These results suggest that TMP might find therapeutic utility as an efficacious antioxidant for the treatment of human cardio-cerebrovascular diseases and warrant further exploration of its actions in whole-animal models and preclinical studies. However, the role of TMP in inhibiting NADPH oxidase remains to be elucidated.

\section{Abbreviations}

Ach: Acetylcholine

ANOVA: Analysis of variance

DETCA: Diethyldithiocarbamic acid

DHE: Dihydroethidium

DPI: Diphenyleneiodonium

EDR: Endothelium-dependent relaxation

$E_{\max }: \quad$ Maximal response

eNOS: Endothelial nitric oxide synthase

GAPDH: Glyceraldehyde 3-phosphate dehydrogenase

$\mathrm{H}_{2} \mathrm{O}_{2}$ : Hydrogen peroxide

IDV: Integrated density value

$\mathrm{O}_{2}{ }^{--}$: $\quad$ Superoxide anion

$\mathrm{pD}_{2}$ : Negative logarithm of the $\mathrm{EC}_{50}$ (drug concentration that induces $50 \%$ of the

Phe: Phenylephrine

ROS: Reactive oxygen species

SDS: $\quad$ Sodium dodecyl sulfate

SEM: $\quad$ Standard error of the mean 


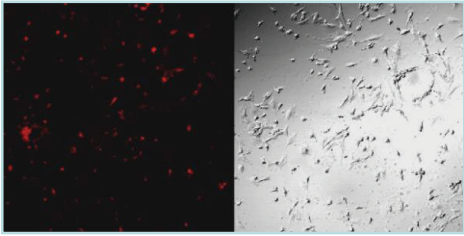

Control

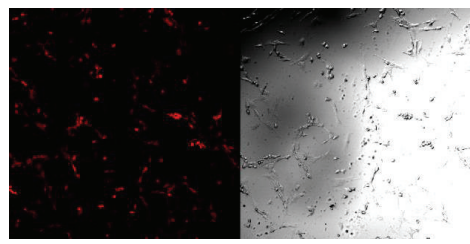

Apocynin $+\mathrm{H}_{2} \mathrm{O}_{2}$

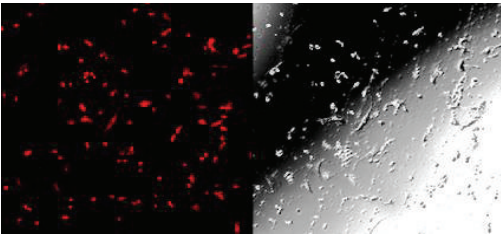

$\mathrm{H}_{2} \mathrm{O}_{2}$

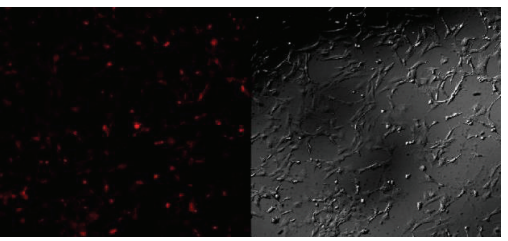

$\mathrm{DPI}+\mathrm{H}_{2} \mathrm{O}_{2}$

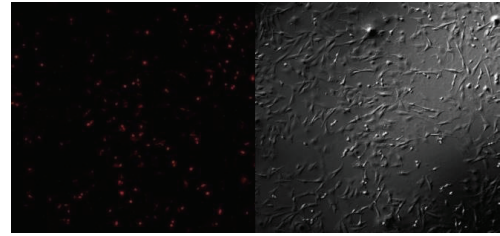

$\mathrm{TMP}+\mathrm{H}_{2} \mathrm{O}_{2}$

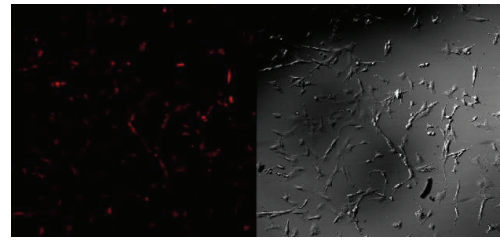

Tiron + DETCA $+\mathrm{H}_{2} \mathrm{O}_{2}$

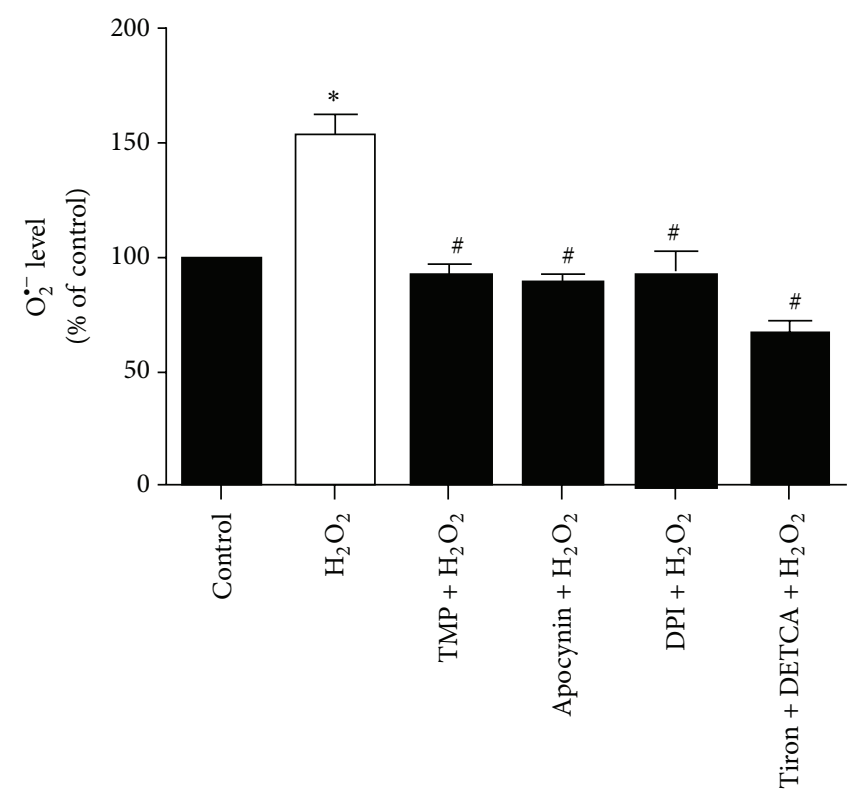

FIgURE 4: Tetramethylpyrazine (TMP), apocynin, diphenyleneiodonium (DPI), and Tiron prevent hydrogen peroxide- $\left(\mathrm{H}_{2} \mathrm{O}_{2}-\right)$ induced production of the superoxide anion $\left(\mathrm{O}_{2}{ }^{--}\right)$in primary rat aortic endothelial cells. $\mathrm{O}_{2}{ }^{--}$production was detected by the dihydroethidium(DHE-) mediated fluorescence microscopy assay. Cells were treated with $\mathrm{H}_{2} \mathrm{O}_{2}(200 \mu \mathrm{M})$ alone or in combination with TMP (10 nM), apocynin $(10 \mu \mathrm{M})$, DPI $(10 \mathrm{nM})$, or Tiron $(10 \mathrm{nM})$ plus diethyldithiocarbamic acid (DETCA) $(1 \mathrm{mM})$ pretreatment. The bar graph shows the fluorescence intensity (\%) of each experimental group relative to the control. Data represent the mean \pm the standard error of the mean (SEM) of 3-9 independent experiments $\left({ }^{*} P<0.05\right.$ versus control; ${ }^{\#} P<0.05$ versus $\left.\mathrm{H}_{2} \mathrm{O}_{2}\right)$.

SOD: Superoxide dismutase

TMP: Tetramethylpyrazine.

\section{Conflict of Interests}

The authors declare that there is no conflict of interests regarding the publication of this paper.

\section{Acknowledgments}

This study was supported by the Guangdong Provincial Natural Science Foundation of China (Grant no. 9451040701003684).

\section{References}

[1] J. Loscalzo, "Oxidant stress: A key determinant of atherothrombosis," Biochemical Society Transactions, vol. 31, no. 5, pp. 10591061, 2003.

[2] M. Mudau, A. Genis, A. Lochner, and H. Strijdom, "Endothelial dysfunction: the early predictor of atherosclerosis," Cardiovascular Journal of Africa, vol. 23, no. 4, pp. 222-231, 2012.

[3] J. Frostegård, "Immunity, atherosclerosis and cardiovascular disease," BMC Medicine, vol. 11, article 117, 2013.

[4] P. Dutta, G. Courties, Y. Wei et al., "Myocardial infarction accelerates atherosclerosis," Nature, vol. 487, no. 7407, pp. 325329, 2012.

[5] L. B. Goldstein, C. D. Bushnell, R. J. Adams et al., "Guidelines for the primary prevention of stroke: a guideline forhealthcare 
professionals from the American Heart Association/American StrokeAssociation," Stroke, vol. 42, no. 2, pp. 517-584, 2011.

[6] P. O. Vandvik, A. M. Lincoff, J. M. Gore et al., "Primary and secondary prevention of cardiovascular disease: antithrombotic therapy and prevention of thrombosis, 9th ed: American college of chest physicians evidence-based clinical practice guidelines," Chest, vol. 141, no. 2, supplement, pp. e637S-e668S, 2012.

[7] A. R. Weseler and A. Bast, "Oxidative stress and vascular function: implications for pharmacologic treatments," Current Hypertension Reports, vol. 12, no. 3, pp. 154-161, 2010.

[8] A. Spychalowicz, G. Wilk, T. Śliwa, D. Ludew, and T. J. Guzik, "Novel therapeutic approaches in limiting oxidative stress and inflammation," Current Pharmaceutical Biotechnology, vol. 13, no. 13, pp. 2456-2466, 2012.

[9] T. Kosuge and H. Kamiya, "Discovery of a pyrazine in a natural product: tetramethylpyrazine from cultures of a strain of bacillus subtilis," Nature, vol. 193, no. 4817, p. 776, 1962.

[10] W. Peng, D. Hucks, R. M. Priest, Y. M. Kan, and J. P. T. Ward, "Ligustrazine-induced endothelium-dependent relaxation in pulmonary arteries via an NO-mediated and exogenous Larginine-dependent mechanism," British Journal of Pharmacology, vol. 119, no. 5, pp. 1063-1071, 1996.

[11] Y. R. Jiang and K. J. Chen, "Pharmacological roles of ligustrazine incardio-/cerebrovascular systems and its progress in researches of clinical application," Chinese Journal of Integrated Traditional and Western Medicine, vol. 33, no. 5, pp. 707-711, 2013.

[12] L. Lv, S.-S. Jiang, J. Xu, J.-B. Gong, and Y. Cheng, "Protective effect of ligustrazine against myocardial ischaemia reperfusion in rats: the role of endothelial nitric oxide synthase," Clinical and Experimental Pharmacology and Physiology, vol. 39, no. 1, pp. 20-27, 2012.

[13] F. Jiang, J. Qian, S. Chen, W. Zhang, and C. Liu, "Ligustrazine improves atherosclerosis in rat via attenuation of oxidative stress," Pharmaceutical Biology, vol. 49, no. 8, pp. 856-863, 2011.

[14] Z. Shao, J. Li, Z. Zhao, C. Gao, Z. Sun, and X. Liu, "Effects of tetramethylpyrazine on nitric oxide/cGMP signaling after cerebral vasospasm in rabbits," Brain Research, vol. 1361, pp. 6775, 2010.

[15] E. Veal and A. Day, "Hydrogen peroxide as a signaling molecule," Antioxidants and Redox Signaling, vol. 15, no. 1, pp. 147-151, 2011.

[16] B. M. Boulden, J. D. Widder, J. C. Allen et al., "Early determinants of $\mathrm{H}_{2} \mathrm{O}_{2}$-induced endothelial dysfunction," Free Radical Biology and Medicine, vol. 41, no. 5, pp. 810-817, 2006.

[17] H. Cai, "Hydrogen peroxide regulation of endothelial function: origins, mechanisms, and consequences," Cardiovascular Research, vol. 68, no. 1, pp. 26-36, 2005.

[18] C. M. Wong, L. M. Yung, F. P. Leung et al., "Raloxifene protects endothelial cell function against oxidative stress," British Journal of Pharmacology, vol. 155, no. 3, pp. 326-334, 2008.

[19] M. Kamper, O. Tsimpoukidi, A. Chatzigeorgiou, M. Lymberi, and E. F. Kamper, "The antioxidant effect of angiotensin II receptor blocker, losartan, in streptozotocin-induced diabetic rats," Translational Research, vol. 156, no. 1, pp. 26-36, 2010.

[20] G. W. Burton, A. Joyce, and K. U. Ingold, "First proof that vitamin $\mathrm{E}$ is major lipid-soluble, chain-breaking antioxidant in human blood plasma," The Lancet, vol. 2, no. 8293, p. 327, 1982.

[21] V. R. Muzykantov, "Targeting of superoxide dismutase and catalase to vascular endothelium," Journal of Controlled Release, vol. 71, no. 1, pp. 1-21, 2001.
[22] M. S. Petrônio, M. L. Zeraik, L. M. Da Fonseca, and V. F. Ximenes, "Apocynin: chemical and biophysical properties of a NADPH oxidase inhibitor," Molecules, vol. 18, no. 3, pp. 28212839, 2013.

[23] A. Sebastian, A. Radermacher Kim, W. M. Kleikers Pamela, W. Kirstin, and H. H. W. Schmidt Harald, "Evolution of NADPH oxidase inhibitors: selectivity and mechanisms for target engagement," Antioxidants \& Redox Signaling, 2014.

[24] X. Y. Tian, L. H. Yung, W. T. Wong et al., "Bone morphogenic protein-4 induces endothelial cell apoptosis through oxidative stress-dependent p38MAPK and JNK pathway," Journal of Molecular and Cellular Cardiology, vol. 52, no. 1, pp. 237-244, 2012.

[25] J. Dong, S. L. Wong, C. W. Lau et al., "Calcitriol restores renovascular function in estrogen-deficient rats through downregulation of cyclooxygenase-2 and the thromboxane-prostanoid receptor," Kidney International, vol. 84, no. 1, pp. 54-63, 2013.

[26] H. Li, S. Horke, and U. Förstermann, "Oxidative stress in vascular disease and itspharmacological prevention," Trends in Pharmacological Sciences, vol. 34, no. 6, pp. 313-319, 2013.

[27] X. Gao, X.-L. Zhao, Y.-H. Zhu et al., “Tetramethylpyrazine protects palmitate-induced oxidative damage and mitochondrial dysfunction in C2C12 myotubes," Life Sciences, vol. 88, no. 1718, pp. 803-809, 2011.

[28] Q. Xu, P. Xia, X. Li, W. Wang, Z. Liu, and X. Gao, "Tetramethylpyrazine ameliorates high glucose-induced endothelial dysfunction by increasing mitochondrial biogenesis," PLoS ONE, vol. 9, no. 2, Article ID e88243, 2014.

[29] H.-J. Wu, J. Hao, S.-Q. Wang, B.-L. Jin, and X.-B. Chen, "Protective effects of ligustrazine on TNF- $\alpha$-induced endothelial dysfunction," European Journal of Pharmacology, vol. 674, no. 2-3, pp. 365-369, 2012.

[30] W. Dröge, "Free radicals in the physiological control of cell function," Physiological Reviews, vol. 82, no. 1, pp. 47-95, 2002.

[31] B. Halliwell, M. V. Clement, and L. H. Long, "Hydrogen peroxide in the human body," FEBS Letters, vol. 486, no. 1, pp. 10-13, 2000.

[32] T. Fukai and M. Ushio-Fukai, "Superoxide dismutases: role in redox signaling, vascular function, and diseases," Antioxidants and Redox Signaling, vol. 15, no. 6, pp. 1583-1606, 2011.

[33] C. H. Coyle, L. J. Martinez, M. C. Coleman, D. R. Spitz, N. L. Weintraub, and K. N. Kader, "Mechanisms of H2O2-induced oxidative stress in endothelial cells," Free Radical Biology and Medicine, vol. 40, no. 12, pp. 2206-2213, 2006.

[34] R. F. Furchgott and P. M. Vanhoutte, "Endothelium-derived relaxing and contracting factors," The FASEB Journal, vol. 3, no. 9, pp. 2007-2018, 1989.

[35] A. Zembowicz, R. J. Hatchett, A. M. Jakubowski, and R. J. Gryglewski, "Involvement of nitric oxide in the endotheliumdependent relaxation induced by hydrogen peroxide in the rabbit aorta," British Journal of Pharmacology, vol. 110, no. 1, pp. 151-158, 1993.

[36] H. Cai, "NAD $(\mathrm{P}) \mathrm{H}$ oxidase-dependent self-propagation of hydrogen peroxide and vascular disease," Circulation Research, vol. 96, no. 8, pp. 818-822, 2005.

[37] A. Schramm, P. Matusik, G. Osmenda, and T. J. Guzik, "Targeting NADPH oxidases in vascular pharmacology," Vascular Pharmacology, vol. 56, no. 5-6, pp. 216-231, 2012.

[38] M. H. Liao, C. C. Wu, and M. H. Yen, "Beneficial effects of tetramethylpyrazine, an active constituent of Chinese herbs, on rats with endotoxemia.," Proceedings of the National Science 
Council, Republic of China. Part B, Life sciences, vol. 22, no. 1, pp. 46-54, 1998.

[39] C.-C. Wu, M.-H. Liao, S.-J. Chen, and M.-H. Yen, "Tetramethylpyrazine prevents inducible NO synthase expression and improves survival in rodent models of endotoxic shock," Naunyn-Schmiedeberg's Archives of Pharmacology, vol. 360, no. 4, pp. 435-444, 1999.

[40] Q. H. Yang, Y. Liang, Q. Xu, Y. Zhang, L. Xiao, and L. Y. Si, "Protective effect of tetramethylpyrazine isolated from Ligusticum chuanxiong on nephropathy in rats with streptozotocininduced diabetes," Phytomedicine, vol. 18, no. 13, pp. 1148-1152, 2011. 


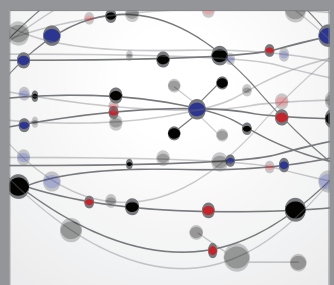

The Scientific World Journal
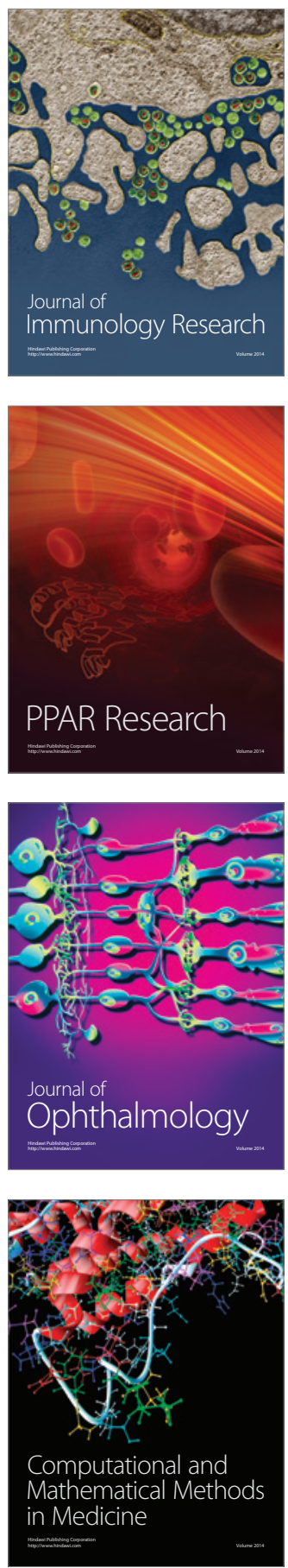

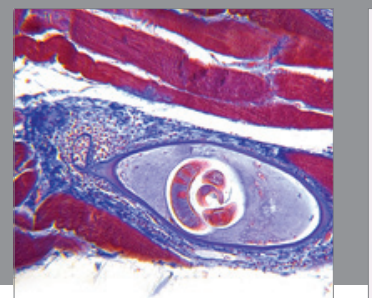

Gastroenterology

Research and Practice
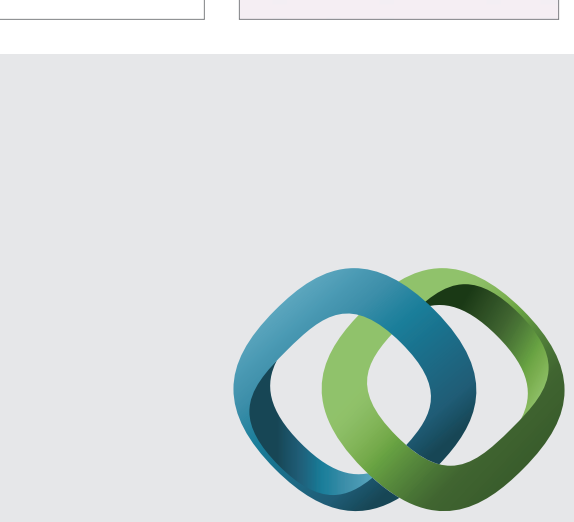

\section{Hindawi}

Submit your manuscripts at

http://www.hindawi.com
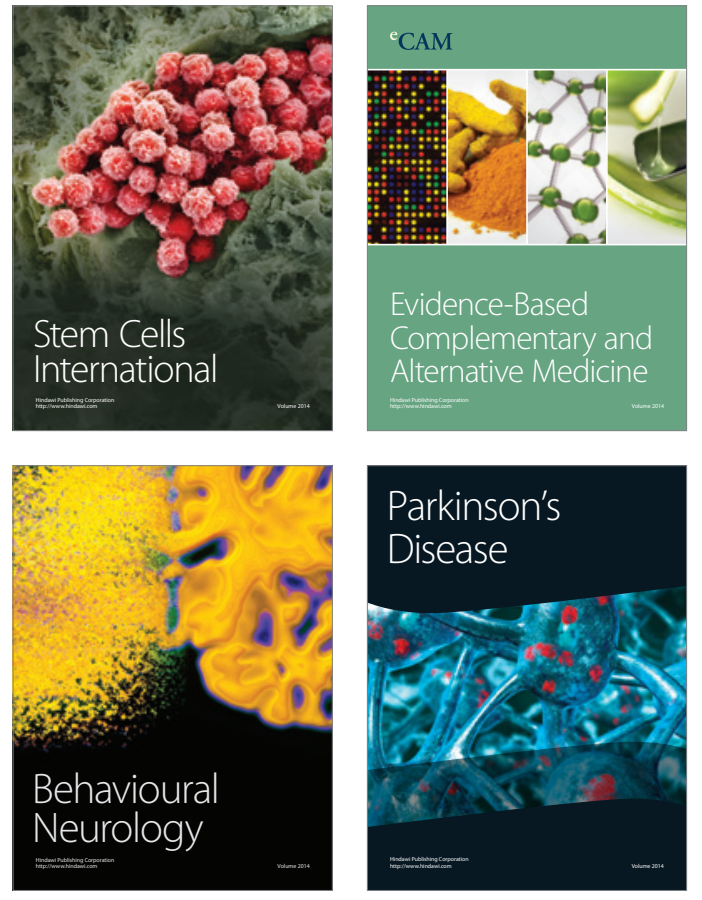
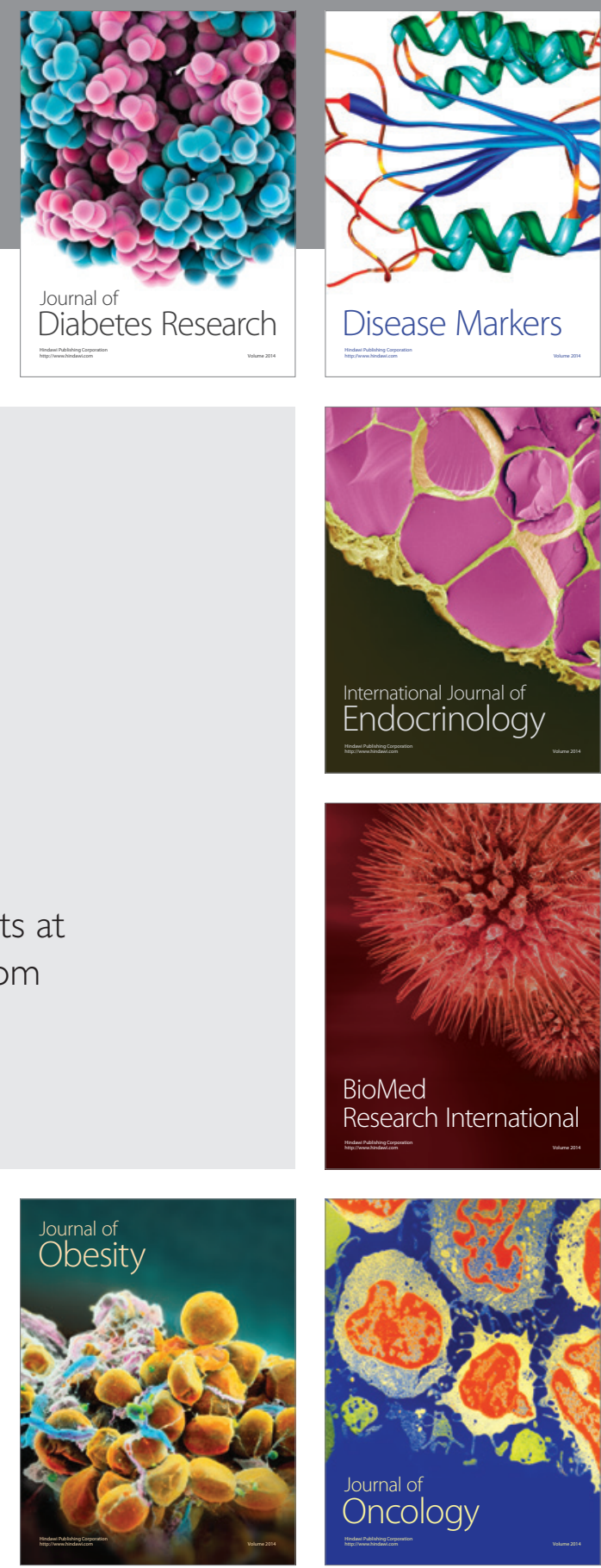

Disease Markers
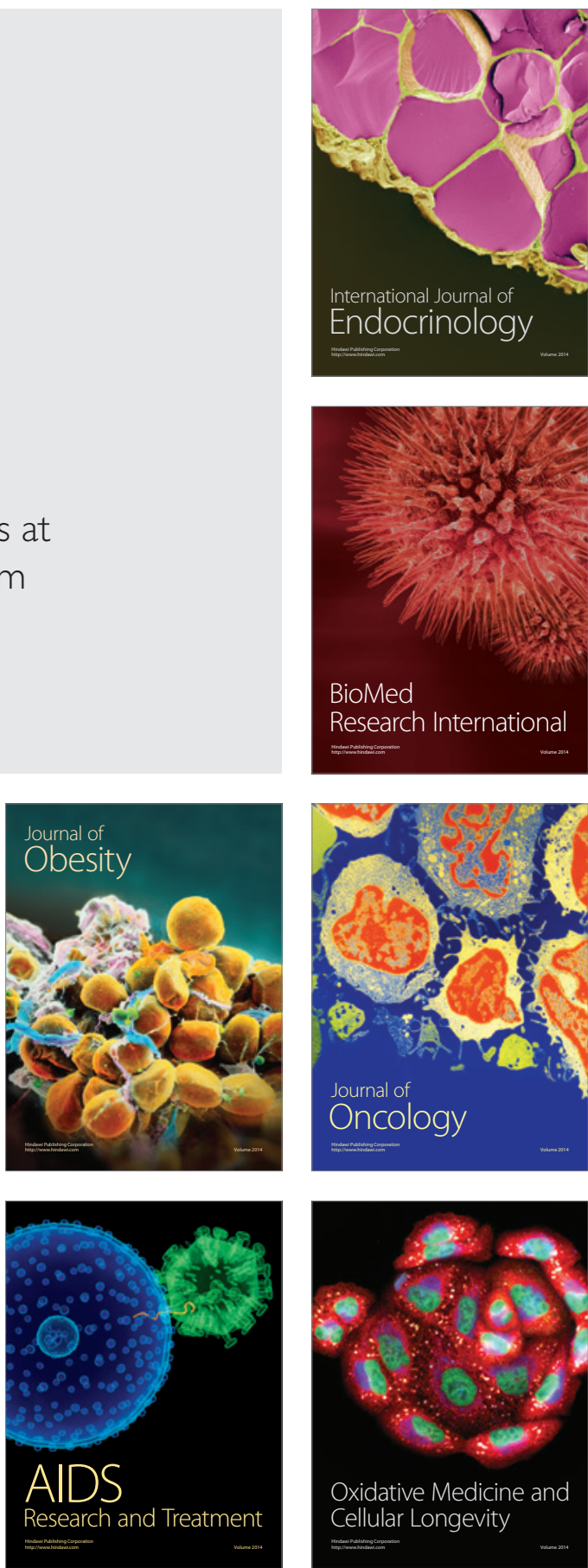